\title{
BMJ Open Evaluating the feasibility of ReWork- SCI: a person-centred intervention for return-to-work after spinal cord injury
}

\author{
Lisa Holmlund (1D ,1,2 Susanne Guidetti (D) , ${ }^{1}$ Claes Hultling, ${ }^{1,3}$ Åke Seiger, ${ }^{1,2}$ \\ Gunilla Eriksson, ${ }^{1,4}$ Eric Asaba ${ }^{1,5}$
}

To cite: Holmlund L, Guidetti S, Hultling $\mathrm{C}$, et al. Evaluating the feasibility of ReWork-SCl: a person-centred intervention for return-to-work after spinal cord injury. BMJ Open 2020;10:e036000. doi:10.1136/ bmjopen-2019-036000

- Prepublication history and additional material for this paper are available online. To view these files, please visit the journal online (http://dx.doi. org/10.1136/bmjopen-2019036000).

Received 25 November 2019

Revised 26 June 2020

Accepted 01 July 2020

Check for updates

(c) Author(s) (or their employer(s)) 2020. Re-use permitted under CC BY-NC. No commercial re-use. See rights and permissions. Published by BMJ.

${ }^{1}$ Department of Neurobiology, Care Sciences and Society, Karolinska Institutet, Huddinge, Sweden

2Rehab Station Stockholm/ Spinalis, R\&D Unit, Rehab Station Stockholm, Stockholm, Sweden

${ }^{3}$ Department of Neurology, Karolinska Universitetssjukhuset, Solna, Sweden

${ }^{4}$ Department of Neuroscience, Rehabilitation Medicine, Uppsala University, Uppsala, Sweden

${ }^{5}$ Research, Education, and

Development Unit, Stockholms

Sjukhem Foundation, Stockholm Sweden

Correspondence to

Dr Lisa Holmlund;

lisa.holmlund@ki.se

\section{ABSTRACT}

Objectives To evaluate the feasibility of: (1) ReWork$\mathrm{SCl}$ with regard to adherence and acceptability and (2) a study design for evaluating ReWork-SCI with regard to recruitment, retention and outcome measures.

Design Pre-test and post-test, single group, feasibility study.

Setting Spinal cord injury (SCl) unit at a regional rehabilitation centre in Sweden.

Participants Two women and five men $(n=7)$. Eligible criteria: (1) sustained traumatic or non-traumatic SCl;

(2) completed the first acute care episode in a hospital;

(3) between 18 to 65 years of age; (4) assessed by a physician as approachable for participation in the intervention; (5) history of permanent or temporary employment; (6) self-reported desire to return to work; and (7) ability to communicate in English or Swedish.

Intervention ReWork-SCl is a person-centred intervention for return-to-work (RTW), developed and evaluated using the Medical Research Council's guidelines. ReWork-SCI follows a person-centred, structured and coordinated intervention process led by a coordinator within a SCl rehabilitation team.

Outcome measures The feasibility of ReWork-SCl and a study design was evaluated using a set of outcome measurement tools, vocational data, logbooks and semistructured interviews.

Results All eligible participants accepted enrolment and follow-up. All participants had a plan for RTW after 3 months and four participants had initiated part-time work or work trial 6 months after commencement of intervention. Adherence and acceptability were overall good. Challenges of the intervention related to the personcentred follow-up, staff shortage and rootedness in the SCl team.

Conclusions ReWork-SCl was feasible and can contribute to a systematic design of an individualised plan, facilitate decision-making and build trust in the RTW process after $\mathrm{SCl}$. Core features of the intervention was the systematic structure, use of a person-centred approach and dialogue with the employer. For the effectiveness of ReWork-SCI, modifications and considerations of study design are needed.

\section{INTRODUCTION}

Return-to-work (RTW) after spinal cord injury (SCI) can be a challenging and complex

\section{Strengths and limitations of this study}

- A strength of this study was that key uncertainties related to the intervention and a study design could be explored prior to further development and effectiveness evaluation.

- Another strength was the integration of quantitative and qualitative data that allowed for adherence and acceptability to be explored from multiple perspectives and thereby giving a broader understanding of intervention components.

- An additional strength was the dynamic approach that allowed for formative modifications and thereby implications for important remodelling of the intervention.

- The small sample enabled the close monitoring but led to limitations to determine if variance can be expected in a future trial.

process. RTW is particularly impacted by physical disability and medical complications following injury, which consequently can lead to a need for adjustments in everyday life. ${ }^{1-5}$ This can imply limited opportunities in the labour market ${ }^{3}$ and low employment rates. ${ }^{6-8}$ Despite an emphasis on the right to work for people with disability, ${ }^{9}$ there is a risk that people with SCI remain outside the labour market, stay unemployed or are granted sick leave/disability pension without access to relevant and fair support in the RTW process. ${ }^{310}$ The process in this study follows the Medical Research Council (MRC) guidelines for developing and evaluating complex interventions. The MRC steers to a non-linear process, where systematic development and feasibility testing are critical before proceeding to a fullscale trial. ${ }^{11}$

Research focussing on interventions to facilitate RTW in general describe a variety of strategies that often differ in design, content and duration. ${ }^{12} \mathrm{~A}$ few systematic reviews explore the effectiveness of different intervention components. ${ }^{12-15}$ Interventions including two to three domains, such as 
health focussed interventions, service coordination or work modifications, are effective in reducing duration of sick leave among people with musculoskeletal, painrelated and mental health conditions. ${ }^{13}$ Moreover, early and multidisciplinary RTW interventions have been effective for a number of target populations, whereas time-contingent services were effective among people with physical complaints. ${ }^{14}$ There is some evidence for the effect of coordination of RTW. ${ }^{13-15}$ However, a recent Cochrane review did not show any effects compared with regular practice. ${ }^{12}$ Intervention research for RTW predominantly focus on the leading causes of sick leave, while evidence for interventions to facilitate RTW after SCI is limited. ${ }^{1617}$ Evidence-based supported employment has shown to be effective in a US veteran population, ${ }^{18} 19$ and early interventions integrated within medical rehabilitation have been evaluated in Australia. ${ }^{20}{ }^{21}$ Common features in the aforementioned studies were the use of a vocational professional and an individualised approach in goal setting and planning. ${ }^{18-21}$ The process evaluation is an essential part of designing and evaluating a complex intervention. ${ }^{22}$ Process evaluations show potential of action-oriented services for persons with $\mathrm{SCI},{ }^{23}$ and a value of early interventions to retain hope for employment after injury, yet with a desire for flexibility and timeliness of the interventions. ${ }^{24} 25$

In development of interventions it is necessary to make use of existing evidence and to scrutinise the challenges in standardising interventions across populations and societal settings. ${ }^{11}$ For example, interventions for RTW are likely to benefit from adaptations to the local context, ${ }^{26}$ such as the specific legislative, insurance and healthcare systems. ${ }^{27}$ Therefore, studies were conducted by the research group in development of ReWork-SCI to explore the experiences of RTW and the RTW process in a Swedish context. ${ }^{3-5} 10$ These studies drew on narratives over time with adults not working early after injury, ${ }^{35}$ participatory research with people working after $\mathrm{SCI}^{4}$ and focus group interviews with professional stakeholders. ${ }^{10}$ The results indicated a risk of delayed, absent or unequal RTW processes ${ }^{3510}$ and people with a SCI needing to find their own paths towards work after injury. ${ }^{4}$ This was due to a fragmented support, and inequalities depending on employment status at the time of injury. ${ }^{3-5} 10$ Conducting a feasibility study prior to evaluating effectiveness is important in order to capture key uncertainties such as potential implementation or design problems. ${ }^{11} 22$ The aim in this study was to evaluate the feasibility of: (1) ReWork-SCI with regard to adherence and acceptability and (2) a study design for evaluating ReWork-SCI with regard to recruitment, retention and outcome measures.

\section{METHODS}

\section{Study design}

A pre-test and post-test, single group design was used to evaluate the aspects of the intervention's feasibility and potential outcomes. ${ }^{28-30}$ The process of the implementation was evaluated by using log books and qualitative interviews. ${ }^{22}{ }^{31}$ Mixed methods can be suitable to address different aspects of feasibility in preparation for a full-scale trial. ${ }^{31}$ Quantitative and qualitative data were collected, analysed and reported separately. The first 6 months of Re-Work-SCI were evaluated as this period was deemed to be the most resource-intense and critical.

\section{Setting}

SCI services in Sweden are currently provided on a Regional level. The first acute care episode is normally provided in a SCI unit at a hospital, while inpatient care and rehabilitation is provided either in a hospital or in a rehabilitation facility. Access to SCI outpatient care, rehabilitation and follow-up varies between Regions. In this study, participants were recruited in a SCI unit providing outpatient care (including day-care, medical follow-up and consultation). Support for RTW is organised by two governmental agencies, the employer and the healthcare service jointly. The Swedish Social Insurance Agency (SSIA) is responsible for monitoring and coordinating the RTW process. The SSIA decides on eligibility for sick leave benefits, granted on $25 \%, 50 \%$ and $75 \%$, and based on a certificate issued by a physician. In addition, the SSIA can grant work-trial for up to 3 months. The employer is responsible to provide an efficient RTW process, to accommodate the employee and to design a plan for RTW within 30 days (if it is assumed that the person will be absent for more than 60 days). For people that are unemployed, the Swedish Public Employment Service (SPES) is responsible for assessments, guidance and preparatory measures for work. In addition to medical care and rehabilitation, the healthcare services are, from February 2020, legally required to provide coordination of RTW. However, coordination is primarily implemented in the primary care services, and not yet provided in, or adapted for, SCI rehabilitation settings and outpatient care.

\section{Development of ReWork-SCI}

According to MRC guidelines, in the development of a complex intervention it is necessary to identify or develop theory and an evidence-base for the intervention. ${ }^{11}$ In ReWork-SCI, theory related to a perspective of what people do in their everyday life contributes to their being, becoming and belonging, ${ }^{32}$ and to a perspective of persons with SCI as experts in the development of healthcare interventions concerning them. ${ }^{33} 34$ The evidencebase derives from the interdisciplinary body of knowledge about RTW programmes and our previous studies ${ }^{3-5} 10$ that are outlined in the introduction. The development and modelling was conducted in three steps: (1) identification of guiding principles and components for ReWork-SCI; (2) modelling of preliminary intervention steps (within the research group); and (3) modelling of the intervention in a collaborative workshop with stakeholders (physician, occupational therapist, social worker, officers from the SSIA and the SPES and persons with SCI). The guiding principles for ReWork-SCI were: (1) 
acknowledgement of the person's experiences; life situation, and context; ${ }^{3-5} 103335$ (2) early but time-sensitive actions; 3510142425 (3) integration and rootedness in the multi-professional team; ${ }^{10} 1420$ (4) systematic structure and coordination of multidisciplinary actions; $;^{34101415}$ (5) support in finding and integrating strategies for everyday life with work; ${ }^{3-5}$ and (6) support in finding strategies for dialogue at the workplace. ${ }^{3} 410$ The components and the intervention steps for ReWork-SCI are outlined in figure 1. The intervention was tailored to complement legislative, social insurance and healthcare systems for RTW in Sweden, as well as provide a systematic way to train an occupational therapist or a social worker in how to function as a coordinator for a person-centred,

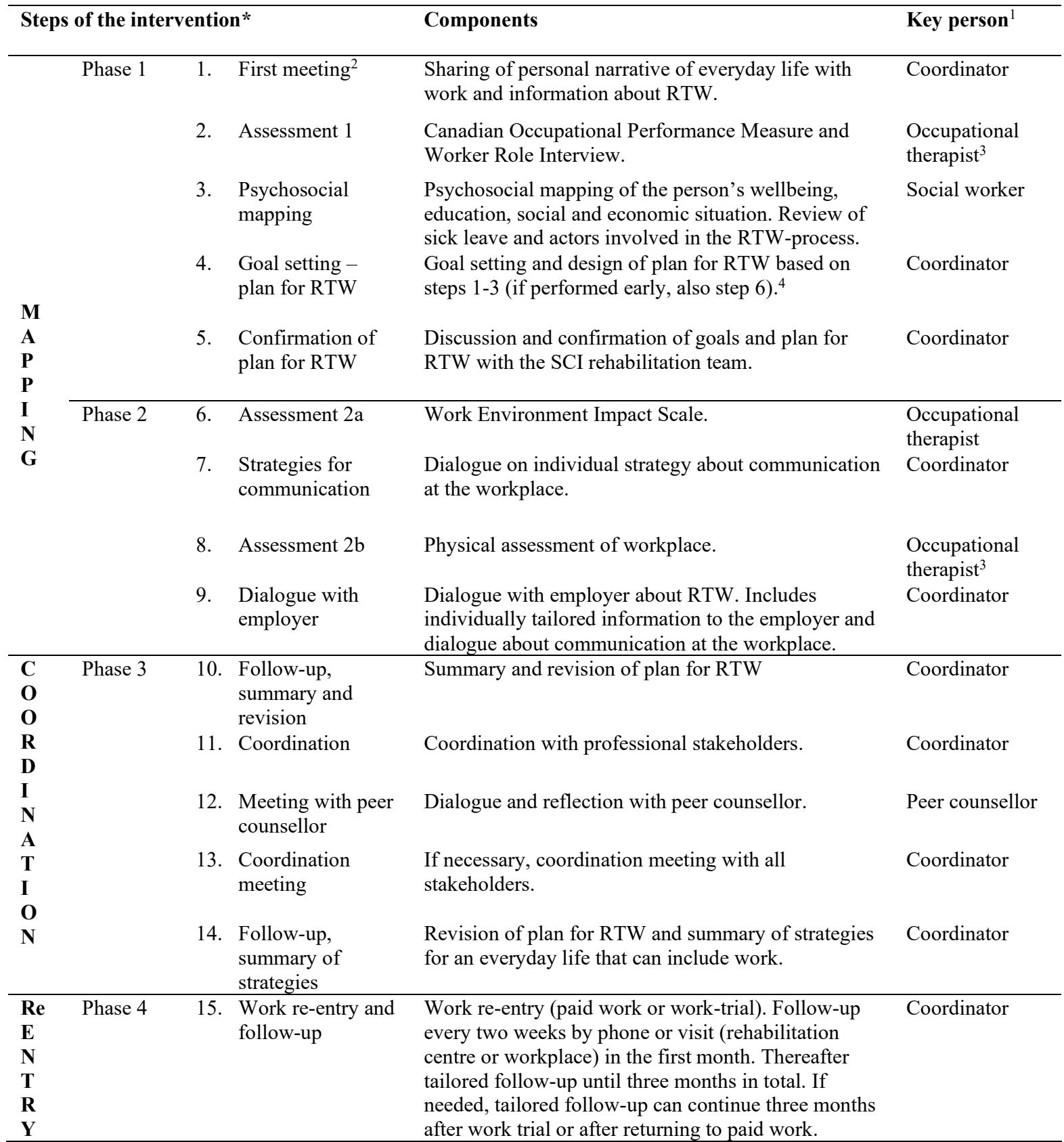

Figure 1 ReWork-SCl, a person-centred intervention for return to work (RTW) after spinal cord injury (SCl). ${ }^{*}$ Revision of plan for RTW and coordination with other stakeholders are ongoing throughout the RTW process. 1. Key person indicates who is responsible to initiate the step; each step always includes the person with SCl. 2. Some steps can be merged, for example, steps 1 and 2, steps 2 and 6 and steps 8 and 9. 3. Both an occupational therapist and a social worker can be a coordinator; steps 2, 3, 6 and 8 require a specific profession. 4 . Some steps are flexible depending on estimated time to work re-entry and personal preferences, for example, steps 6 and 12 can be performed earlier. 
structured and coordinated RTW process in a SCI unit. The coordinator collaborates with the person with SCI and other stakeholders in (1) designing a plan for RTW and (2) finding strategies for an everyday life after SCI where paid work could be included.

\section{Sampling and recruitment}

Sample size

In this feasibility study, a prospective sample size was not calculated. Six to ten participants and two coordinators were deemed sufficient to evaluate the feasibility of ReWork-SCI with regard to adherence, acceptability, recruitment, retention and outcome measures. ${ }^{36}$

\section{Participants}

Eligibility criteria for persons with SCI consisted of: (1) sustained traumatic or non-traumatic SCI; (2) completed the first acute care episode in a hospital; (3) between 18 to 65 years of age; (4) assessed by a physician as approachable for participation in the intervention; (5) history of permanent or temporary employment; (6) self-reported desire to return to work; and (7) ability to communicate in English or Swedish. Enrolment of people at the SCI unit, admitted to day-care after onset of SCI or listed for 1 year medical follow-up, occurred during two consecutive phases (October 2017 and January 2018). People matching eligibility criteria received brief information verbally by a team-member at the centre and were asked if they wanted to be contacted by the first author for further information. Thereafter, they received verbal information via telephone along with written information via mail and were offered a meeting for further questions and consent. Five men and two women were recruited $(n=7)$. Demographic characteristics are described in table 1. All worked full-time prior to the SCI and when the intervention commenced, they were between 95 and 430 days after SCI (table 2). Based on the severity of SCI and type of employment (table 1) four participants had opportunities to return to their previous workplace and duties, two had opportunities to return to their workplace with major accommodations and one could not return to his/ her previous workplace or duties.

\section{Coordinators}

Criteria for coordinators delivering the intervention were: (1) being an occupational therapist or a social worker and (2) having expertise in SCI rehabilitation. Professionals working at the regional rehabilitation centre were invited to a 3-day training workshop (October 2017) to learn how to deliver ReWork-SCI. Two social workers and two occupational therapists participated in the training. One occupational therapist was appointed to be a coordinator in the study by the management of the rehabilitation centre. One additional occupational therapist participated in a training workshop (May 2018) and assumed responsibility as coordinator after the first coordinator terminated her employment at the rehabilitation centre.
Table 1 Participants' demographic characteristics at baseline $(n=7)$

\begin{tabular}{|c|c|}
\hline Age, years, mean (range)/median & $51(33-62) / 54$ \\
\hline Gender, men/women, n & $5 / 2$ \\
\hline Civil status, living together/single, $\mathrm{n}$ & $1 / 6$ \\
\hline Children, yes/no, n & $5 / 2$ \\
\hline Children living at home, yes/no/partly, $\mathrm{n}$ & $2 / 2 / 1$ \\
\hline Born in Sweden, yes/no, $n$ & $6 / 1$ \\
\hline Cause of injury, traumatic/non-traumatic, $n$ & $4 / 3$ \\
\hline \multicolumn{2}{|l|}{ Severity of $\mathrm{SCl}$ neurology, $\mathrm{n}$} \\
\hline C1-C8 AIS A, B or C & 1 \\
\hline T1-S5 AIS A, B or C & 4 \\
\hline AIS D any level & 2 \\
\hline Impairment type, tetraplegia/paraplegia, n & $3 / 4$ \\
\hline \multicolumn{2}{|l|}{ Time since injury, $\mathrm{n}^{\star}$} \\
\hline $1-90$ days & 0 \\
\hline $90-180$ days & 4 \\
\hline 180-364 days & 2 \\
\hline$>365$ & 1 \\
\hline $\begin{array}{l}\text { Level of education, elementary school/ } \\
\text { upper secondary school/university, } n\end{array}$ & $1 / 4 / 2$ \\
\hline $\begin{array}{l}\text { Occupational status prior to } \mathrm{SCI}, \\
\text { permanent employment/temporary } \\
\text { employment/unemployed, } \mathrm{n}\end{array}$ & $6 / 1 / 0$ \\
\hline $\begin{array}{l}\text { Type of occupation prior to } \mathrm{SCl} \text {, sedentary/ } \\
\text { manual labour, } \mathrm{n}\end{array}$ & $4 / 3$ \\
\hline SOC-13, mean (range)/median (q1, q3) & $\begin{array}{l}65(55-75) / 70 \\
(56,74)\end{array}$ \\
\hline
\end{tabular}

*At start of intervention, divided according to time limits in the rehabilitation chain in Sweden.

AIS, American Association Impact Scale; SCI, spinal cord injury; SOC-13, 13 item Sense of Coherence Scale.

\section{Data collection}

Data were collected at baseline, start of ReWork-SCI, as well as 3 and 6 months after start of ReWork-SCI (figure 2). Basic demographic data and injury-related data were collected at baseline (table 1). The assessment of severity of SCI neurology followed the American Association Impact Scale ${ }^{37}$ Data collection occurred face-to-face in a location chosen by each participant, normally at the rehabilitation centre or in the participant's home. Injuryrelated data were collected from the medical records.

\section{Measures}

Data related to vocation were collected at baseline and at 3 and 6 months follow-up (tables 1 and 3). Work re-entry were divided into, return to paid work at $\geq 25 \%$ of preinjury working hours or work trial at $\geq 25 \%$ of pre-injury working hours, with compensation from the SSIA or the SPES. In addition, the Swedish versions of the following measurement tools were used: 
Table 2 Participation in and adherence to ReWork-SC

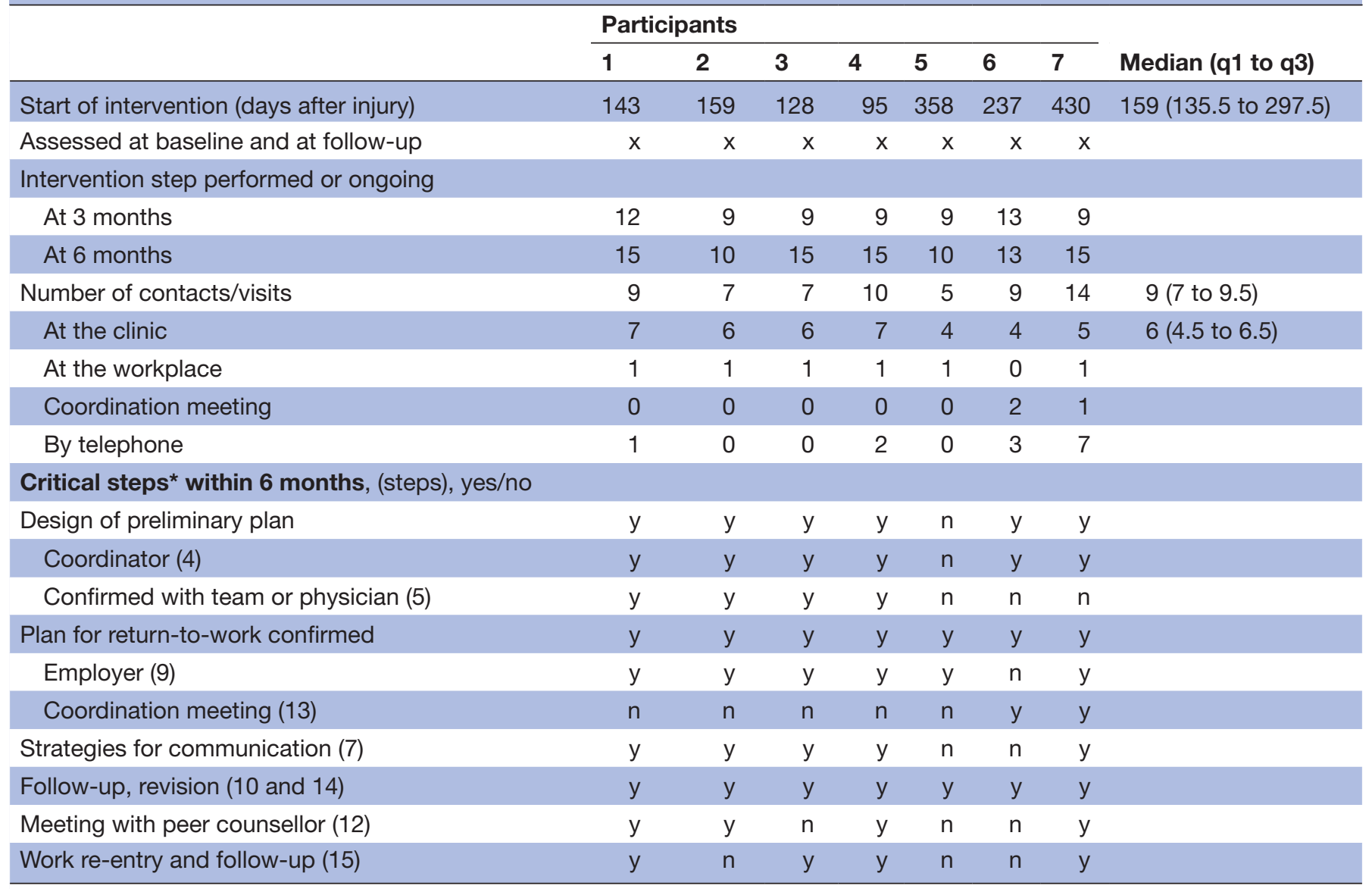

${ }^{*}$ Critical steps imply steps that were not performed together with all participants or steps that were not performed according to the intervention (follow-up, steps 10 and 14).

$\mathrm{SCl}$, spinal cord injury.

Canadian Occupational Performance Measure (COPM) enables to identify and prioritise the problem areas in everyday life. Each defined problem area is scored ( 0 to 10) in regards to importance, performance and satisfaction. ${ }^{38} 39$ Focus was on what the person wanted to, needed to and was expected to perform in everyday life at work.

Worker role interview (WRI) addresses psychosocial and environmental factors that impact RTW. It consists of 6 areas and 16 items, rated from 1 to 4 , indicating how factors interfere (1 and 2) or support (3 and 4) RTW. ${ }^{40} 41$ Item 2, expectation of job success, is a predictor of job potential. $^{42}$

Work Environment Impact scale (WEIS) addresses the fit between the environment and the person. It consists of 17 items, rated from 1 to 4, depending on how the person subjectively experiences that the work environment interferes (1 and 2) or supports (3 and 4) with his/her work performance, satisfaction and well-being. ${ }^{43} 44$

Life Satisfaction Questionnaire (LiSat-11) assesses satisfaction with life as a whole, and with 10 domains of life; each domain is graded from 1 to $6{ }^{45}$ In this study the global question alone, satisfaction with life as a whole, was chosen as this item significantly correlates to 9 of the 10 domain-specific items. ${ }^{46}$ Grades 1 to 4 are dichotomised as not satisfied and grades 5 and 6 as satisfied. ${ }^{45}$

Self-Efficacy scale is developed on the basis of a theoretical framework on behavioural change, ${ }^{47}$ and consists of everyday life activities. Each item is scored between 1 'not being confident at all in my ability' and 10 'being very confident in my ability'. ${ }^{48}$ In this study an adapted version with 18 items was used.

EuroQol-5 Dimensions (EQ5D-3L) describes and values health-related quality of life. It includes five dimensions of health and three levels of severity for each dimension. It also includes a Visual Analogue Scale (EQ-VAS), on which people rate their health state (0 to 100). ${ }^{49} 50$

13-item Sense of Coherence Scale (SOC-13) addresses components theorised to impact on a person's resources to cope with stressors and manage tensions. ${ }^{51}$ It contains 13 items rated between 1 and $7 .{ }^{5253}$

Functional Independence Measure (FIM), is an indicator of disability. FIM contains 6 domains divided into 18 motor and cognitive items scored from 1 , total dependence, to 7 , total independence. The total score therefore ranges between 18 and $126 .^{5455}$ 


\section{Baseline}

- Demographic characteristics and injury-related data

- Vocational data

- SOC-13

- Lisat-11, Self-Efficacy Scale, EQ5D, EQ-VAS, FIM

\section{Start of intervention}

- Canadian Occupational Performance Measure

- Worker Role Interview

-Work Environment Impact Scale

\section{Three months follow-up}

- Vocational data

-Lisat-11, Self-Efficacy Scale, EQ5D, EQ-VAS, FIM

- Interviews with participants and coordinator

\section{Six months follow-up}

- Vocational data

-Lisat-11, Self-Efficacy Scale, EQ5D, EQ-VAS, FIM

- Canadian Occupational Performance Measure

- Interviews with participants and coordinator

Figure 2 Timeline for data-collection. EQ5D, EuroQol5 Dimensions; EQ-VAS, EuroQol Visual Analogue Scale; FIM, Functional Independence Measure; Lisat-11, Life Satisfaction Questionnaire; SOC-13, 13 item Sense of Coherence Scale.

Table 3 Participants' baseline and outcomes at 3 and 6 month's follow-up $(n=7)$

\begin{tabular}{|c|c|c|c|}
\hline & Baseline & 3 months & 6 months \\
\hline Sick leave, full-time/part-time, $n$ & $7 / 0$ & $5 / 2$ & $4 / 3$ \\
\hline Paid work, full-time/part-time, $n$ & $0 / 0$ & $0 / 1$ & $0 / 3$ \\
\hline Home help services, yes/no, n & $4 / 3$ & $4 / 3$ & $3 / 4$ \\
\hline Assistance P-ADL, yes/no, $n$ & $1 / 6$ & $1 / 6$ & $1 / 6$ \\
\hline Transport with own cart, yes, $\mathrm{n}$ & 2 & 4 & 3 \\
\hline Self-Efficacy scale, median ( $q 1$ to $q 3$ ) & 127 (109 to 143$)$ & 130 (128 to 140$)$ & 122 (116 to153) \\
\hline EQ5D, median (q1 to q3) & 0.684 (0.679 to 0.739$)$ & $0.679(0.612$ to 0.698$)$ & 0.679 (0.646 to 0.679$)$ \\
\hline EQ VAS (0-100), median (range) & $55(30-70)$ & $45(30-65)$ & $45(20-50)$ \\
\hline Performance & 5 (2 to 6.5$)$ & - & 5 (3 to 7$)$ \\
\hline Satisfaction & 2 (2 to 4.5$)$ & & 4 (2 to 6$)$ \\
\hline
\end{tabular}

*At 6 months follow-up one participant had already finished a work trial.

†All participants had access to and used transportation services.

COPM, Canadian Occupational Performance Measure; EQ5D, EuroQol-5 Dimensions; EQ-VAS, EuroQol Visual Analogue Scale; FIM, Functional

Independence Measure; Lisat-11, Life Satisfaction Questionnaire; P-ADL, personal activities of daily life. 
Feasibility of ReWork-SCl and study design

Recruitment and retention were registered in a research $\log$ by the first author. Number of contacts, performed steps and time needed to perform ReWork-SCI were registered in logbooks kept by the coordinators. Semistructured interviews were conducted with the first coordinator and with the participants to generate information on the acceptability of ReWork-SCI. The questions related to their experiences of delivering the intervention and participating in the intervention. The interviews lasted 15 to $45 \mathrm{~min}$ and were recorded digitally. The coordinators could contact the first author for clarifications about ReWork-SCI (telephone or face-to-face meetings). In this way, a dynamic approach was used to clarify or modify components of ReWork-SCI during the study. ${ }^{31}$ All adaptations were logged by the researcher and documented for the coordinators.

\section{Analyses}

Descriptive statistics were used to present demographic characteristics and outcome at 3-month and/or 6-month follow-up. EQ5D was analysed by the use of the Swedish experience-based value sets. ${ }^{50} \mathrm{COPM}$ scores on an individual level were analysed to determine clinically meaningful change between start of intervention and 6-month follow-up, that is, >two-point difference in total mean score. ${ }^{39}$ The transcribed data from interviews were analysed according to thematic analysis. ${ }^{56} 57$ Analyses began with the first author reading through the data to identify patterns and themes in the material. In this process questions were posed to the data, such as, 'can this study be done', 'what seem to be the active components' and 'what are the potential challenges and flaws with ReWork-SCI'? This was followed by initial coding where lines or chunks of data were coded with a word or a phrase that remained close to the data. Coding proceeded to a process of constant comparison of codes and merging of codes when they referred to the same experience. Coding themes were continuously discussed between the co-authors (LH, GE, SG and EA). All researchers involved in analysis had clinical and/or research experience of RTW and SCI rehabilitation. The systematic back and forward process resulted in four themes. ATLAS.ti was used to sort and organise data. ${ }^{58}$

\section{Patient and public involvement statement}

Persons living with SCI were involved in the design of ReWork-SCI through their participation in a collaborative workshop. The workshop focussed on modelling a preliminary intervention as described.

\section{RESULTS}

\section{Recruitment and retention}

All eligible individuals agreed to participate in the study, including follow-up after 3 and 6 months. Recruitment was estimated as being one participant per 2 to 3 weeks.

\section{Adherence}

Table 2 summarises participation in, and adherence to ReWork-SCI. The duration of visits at the clinic ranged from 15 to $45 \mathrm{~min}$ and workplace visits from 60 to $90 \mathrm{~min}$. Steps 1 to 3 were performed with all participants, and steps $6,8,9$ and 10 were performed with all participants except one, who could not return to the previous workplace. Follow-up (steps 10, 14 and 15) varied in content, timing and regularity. These steps were therefore clarified and modified later in the process. Similarly, steps 7, 9 and 11 were clarified and/or modified. For example, information to the employer was important prior to the workplace visit and the structure and content of this meeting had to be clarified. The coordinator merged step 1 with COPM assessment and step 8 with step 9. In addition to the possibilities of merging steps in ReWork-SCI, the coordinator often merged steps 4 and 7 and step 10 with information about the peer counsellor.

\section{Acceptability}

Four themes were identified regarding how ReWork-SCI was accepted by the coordinators and the participants: structure and sharing were critical for decision-making; sharing a new situation with the employer and planning forward; coordination of RTW according to individual needs; and maintaining partnership and collaboration in a complex process.

\section{Structure and sharing were critical for decision-making}

The coordinator expressed that the structure, listening to the participants' personal narratives (step 1) and use of person-centred assessments (steps 2 and 6), enabled an in-depth understanding of a person's situation. The coordinator said: 'The project has meant that one gains an even broader picture of the persons one works with.' The participants appreciated the shared information in the initial phase (step 1) that led to their questions about the RTW process being more clearly defined. Structure and sharing were experienced as conducive to facilitate design of a RTW plan and a shared decision-making process. One participant said: 'I think it has been my goals and we have agreed...well, we do like this and continue like this. Good information.' However, the coordinator and participants also described an ambiguity in relation to the person with SCI being ready for work or not. The coordinator negotiated early initiation of the RTW process in relation to the patients' needs to prioritise basic everyday life occupations and sometimes expressed a wish to cooperate more with the SCI rehabilitation team to determine timeliness. Yet, the participants did not express feelings of pressure to return early, but rather a trust in the flexibility of the process and implementation of the plan for RTW when the timing was right.

Sharing a new situation with the employer and planning forward Both the coordinator and the participants highlighted the dialogue between the coordinator, the person with SCI and the employer (step 9) as central in ReWork-SCI. The 
coordinator facilitated a first formal dialogue between the person and the employer about work re-entry. The coordinator said: 'It has felt very professional to sit there (at the persons workplace) and share this information about SCI, give them that knowledge and leave room for questions.' The support of a third party facilitated sharing the person's experiences of illness or injury, and their everyday situation. The meeting meant sharing information about the SCI and the workplace, and thereby initiating a dialogue about needs and resources, for example, about accommodations. One participant said: 'Having a third party at the meeting was very valuable for me. Then I don't need to be the only one to account for my situation.' The coordinator identified the comprehensive mapping (steps 1 to 6 ) and a preparatory dialogue with the person with SCI (step 7) as important steps prior to the dialogue with the employer. The dialogue meant that the plan for RTW could be more detailed in terms of accommodations related to work tasks, working schedule or the physical environment.

\section{Coordination of RTW according to individual needs}

All participants had either no or only occasional telephone contacts with officers at the SSIA during the intervention. Moreover, most of them experienced a gradual reduction of contacts with the SCI rehabilitation team. Coordination between professional stakeholders was described as the most challenging part of ReWork-SCI by the coordinator. However, the early phases of ReWork-SCI (I and II) had generated knowledge that clarified a level of communication and coordination and the participants experienced a flow in the RTW process. Communication with the SSIA via sick leave certification was sufficient for some. Coordinating meetings-involving the SSIA and the employer (or the SPES) - were deemed necessary if work ability was uncertain or if it was impossible for the person to return to his/her previous work tasks. Despite the time needed for coordination, the coordinator reflected positively on the individualised process: 'Yes, it was unexpectedly flexible... or, like everything in this project there is administration, or to make ends meet... but it works.' Likewise, the participants experienced that the dialogue with a peer counsellor (step 12) needed to be individualised. For some participants, meeting a peer was one of the most critical steps of ReWork-SCI. They appreciated meeting face-to-face with a person they could identify with and discuss aspects specifically related to RTW. One participant said: 'One gets a sense of how others that are ahead of me, how they have tackled... or have known what they need to tackle.' Others declined this opportunity, either because of difficulty identifying with the peer counsellors available, or that peers working at the centre fulfilled the needs. In some cases there was simply a lack of time for more visits.

\section{Maintaining partnership and collaboration in a complex process}

Shared influence in the RTW process was clear for the participants and the coordinator, and not different from common practice. Yet at 3 months follow-up, goals and strategies set in Phase I were unclear to most participants. One participant said: 'The goals, was it about the car and kitchen and work? What were they [the goals]? I don't remember.' Further, the coordinator experienced follow-up (steps 10, 14 and 15) as uncertain. Instead of following the structure for follow-up, the coordinator focussed on general questions and practical solutions such as, prescription of technical aids, referrals to other team members and contact with other professional stakeholders. The coordinator reflected over a lack of detailed guidance in these steps: 'One does this huge mapping, with a lot of information, good information... but it was a bit thin at the end, when the persons were in work-trial.' Consequently, structured revision of the plan for RTW did not occur and the person with SCI was at times alone in finding solutions for everyday life with work. Moreover, the new and not yet established coordinator role meant that the person with SCI was uncertain about when to turn to the coordinator. Similarly, the team members lacked awareness of when to direct the person to the coordinator. Inadvertently, a lack of structure regarding follow-up became a barrier to maintained partnership and collaboration between the person and the coordinator.

\section{Outcome measures}

Participants' demographic characteristics are summarised in table 1. Outcomes at 3 and/or 6 months are presented in tables 3 and 4 . At 6 months follow-up, four of seven participants had returned to work or had pursued a work trial at their workplace. Three participants had returned to part-time work in pre-injury work duties and one participant had engaged in a work trial for a new assignment at the workplace. One participant was waiting to start a work trial in a new position assigned by the SPES. For two participants, secondary complications of the SCI had meant that their plans for RTW was postponed. On a group level there was a clinically meaningful change between baseline and 6 months follow-up for the COPM satisfaction component. On an individual level (table 4), three of the participants showed a two-point increase and one participant a clinically meaningful decrease for the COPM satisfaction component. ${ }^{39}$ One participant showed a clinically meaningful increase in the performance component. WRI item 2, expectation of job success, was assessed to interfere with RTW for participants two and seven. Likewise, WEIS item 13, physical arrangements, was assessed to interfere with satisfaction of work performance for them; both had manual labour. WRI item 11, daily routines, was assessed to interfere with RTW for all participants. WEIS item 2, task demands, was assessed to interfere with satisfaction of work performance for five of six participants. WEIS was deemed not suitable for participant six because it was not possible for this participant to return to the previous job. WRI and WEIS are presented in online supplementary files 1 and 2. 
Table 4 COPM (0 to 10) at start of ReWork-SCl and at 6 months follow-up, total score (mean)

\begin{tabular}{lllll} 
Participant & $\begin{array}{l}\text { Number of } \\
\text { problems, } \mathbf{N}\end{array}$ & $\begin{array}{l}\text { COPM baseline, } \\
\text { performance/satisfaction }\end{array}$ & $\begin{array}{l}\text { COPM } 6 \text { months, } \\
\text { performance/satisfaction }\end{array}$ & $\begin{array}{l}\text { COPM change, performance/ } \\
\text { satisfaction }\end{array}$ \\
\hline 1 & 4 & $19(4.75) / 7(1.75)$ & $22(5.5) / 16(4)$ & $0.75 / 2.25^{*}$ \\
2 & 3 & $23(7.7) / 19(6.3)$ & $19(6.3) / 15(5)$ & $-1.4 /-1.3$ \\
3 & 4 & $19(4.75) / 13(3.25)$ & $26(6.5) / 19(4.75)$ & $1.75 / 1.5$ \\
4 & 5 & $14(2.8) / 11(2.2)$ & $24(4.8) / 23(4.6)$ & $2^{*} / 4.4^{*}$ \\
5 & 5 & $26(5.2) / 20(4)$ & $31(6.2) / 31(6.2)$ & $1 / 2.2^{*}$ \\
6 & 5 & $26(5.2) / 26(5.2)$ & $19(3.8) / 22(4.4)$ & $-1.4 /-2.2^{*}$ \\
7 & 5 & $8(1.6) / 5(1)$ & $9(1.8) / 5(1.1)$ & $0.2 / 0$ \\
\hline
\end{tabular}

${ }^{*}$ Clinically meaningful change.

COPM, Canadian Occupational Performance Measure; SCI, spinal cord injury.

\section{DISCUSSION}

This study aimed to evaluate the feasibility of a personcentred intervention for RTW after SCI and a study design for evaluating the intervention. Acceptability and adherence of the intervention were good, although challenges were identified related to the person-centred follow-up, staff shortage and rootedness in the team. Retention was also good, but recruitment needs to be further considered prior to the design of an effectiveness study.

The strength of this study was the use of both quantitative and qualitative methods, which contributed to understanding the feasibility of ReWork-SCI in a clinical setting. For example, the integration of logbooks along with repeated interviews gave valuable information about adherence and acceptability of ReWork-SCI. The dynamic approach allowed to integrate modifications of the intervention in order to remodel and ensure a good intervention-context fit. ${ }^{31}$ There is no definitive sample size recommended for feasibility studies ${ }^{36}$ but the authors deemed that 6 to 10 participants was sufficient to address the feasibility of the intervention and study design. The inclusion of seven participants enabled close monitoring of the intervention, although a larger sample would have been necessary to provide greater precision of scores for the outcome measures used ${ }^{36}$ and as a basis for sample size calculation. Moreover, blinding of the data collectors (LH and EA) needs to be addressed in future studies. Coding of qualitative data was performed by the first author and continued analysis was discussed among co-authors (LH, SG, GE and EA), all with experience in qualitative research. This enhances the trustworthiness of the results. Generalisability was limited by the small sample and that the participants resided in an urban setting, yet certain aspects of the findings, such as intervention components and steps, may be applicable to other settings. No added risks of harm were assessed as relevant in the context of ReWork-SCI. Participation was granted by a physician and all participants had access to usual care. Initiation of parttime work and work trial was communicated between all stakeholders.

Regarding adherence and acceptance, it is of interest to discuss the person-centred approach and the dialogue with the workplace used in ReWork-SCI. This seemed to facilitate joint decision-making and establishing a plan for RTW. Establishing situations of trust in which the coordinator and person with SCI could share, collaborate and jointly make decisions was critical in being transparent across phases of the study. This is in line with research by Ranner et al implicating how sharing ${ }^{59}$ and transparency ${ }^{60}$ are core elements in enabling awareness and ownership in a rehabilitation process. Further, workplace-based interventions are critical for RTW. ${ }^{61} 62$ Arends et $a l^{63}$ showed how a problem-solving intervention with the support of occupational healthcare providers is effective for persons who return to work after sick leave due to common mental disorders. Including healthcare professionals' competencies in an early dialogue between the person on sick leave and the employer can lead to on-site education that alleviates uncertainties at the workplace. ${ }^{4}$ Yet there is limited research on the effectiveness of workplace-based interventions for persons with SCI. Further exploration of a structured dialogue is therefore an important part of future studies. Another finding is that the use of COPM did not give the expected outcome of active participation in goal setting ${ }^{64}$ since the participants had difficulties recalling their goals. This suggests a need to review the training of coordinators in relation to the use of COPM and to monitor this process in future studies.

ReWork-SCI functioned as a multi-domain intervention $^{13}$ using coordination of RTW between the healthcare services and other stakeholders. This is in line with research on the use of a vocational professional in the RTW process after SCI. ${ }^{18-21}$ Our study contributes with detailing intervention components and steps, and proposing a structure for a RTW intervention after SCI, adapted for a Swedish setting. Standardised intervention components deriving from an evidence-base and adapted for the specific setting are important for the effectiveness of an intervention. ${ }^{11}$ In addition, this study highlights steps of ReWork-SCI that need to be revisited in future studies; that is, confirmation of the plans for RTW with the SCI rehabilitation team, and follow-up. These steps were challenged by lack of rootedness in 
the rehabilitation team, unclarities in how to deliver follow-up steps, staff shortage and staff turnover among coordinators. In line with this, Johnston $e t a l^{25}$ point to the importance of rootedness in the team, programme flexibility and staff communication when implementing a RTW intervention in SCI rehabilitation. A clear structure for the RTW process rooted in the SCI team and integrated in the local context as well as regulations have a potential to safeguard support for RTW after SCI, despite staff turnover. ${ }^{22}$ Therefore, in future studies on ReWork-SCI, the context and setting in which the intervention will be implemented needs further attention. ${ }^{65}$ Follow-up is critical to revisit because rehabilitation after SCI means adjustment to a new life situation. ${ }^{66}$ After SCI further education or training can be necessary for the person to return to work ${ }^{67}$ and consequently, the time to first job can be extended. ${ }^{67}$ Perseverance and structure in follow-up, especially for those in need of new employment or who suffer from secondary complications due to the SCI, is therefore important in order to avoid delayed or absent RTW processes after SCI.

All participants had a plan for RTW at the 3-month follow-up. At the 6-month follow-up, four of seven participants had returned to work or had pursued a work trial, additionally one was waiting to start a work trial. Moreover, there was a clinically meaningful change in the COPM satisfaction component on a group level compared to baseline. Overall, these results point to the feasibility of ReWork-SCI. FIM, Lisat-11, Self-Efficacy scale and EQ5D did not show any change from baseline to 6-month follow-up. This could be due to the small sample, the short duration to follow-up and/or that the intervention did not specifically target these outcomes. Based on our findings, RTW is likely the most suitable primary outcome in future studies, while COPM would be suitable as a secondary outcome. FIM, Lisat-11, Self-Efficacy scale and EQ5D might best be used to describe the characteristic of the sample. In line with research on clinical utility of $\mathrm{WRI}^{68}$ and $\mathrm{COPM}^{69}$ these measures, together with WEIS, were perceived to support decision-making and development of a plan for RTW. To incorporate training of staff in the use of WRI and WEIS can therefore be beneficial, as well as further consideration about if these instruments should primarily function as clinical assessment tools. All eligible persons accepted participation and all participants agreed to follow-up. The initially estimated recruitment of one participant per week was adjusted to one participant per 2 to 3 weeks. This was due to employee turn-over among coordinators and staff shortage. There is one previous high-quality study that evaluates competitive employment for persons with SCI, which included a sample of 201 participants (based on a power-calculation of 126 participants).$^{19}$ Research show that the crude incidence rate of traumatic SCI ( $\geq 18$ years of age) in Stockholm is 19 per million. ${ }^{70}$ The small SCI population in Sweden implies challenges to reach a sufficient sample for an efficacy study; to enable this, including multiple sites would be necessary.
There is a critical need of high-quality studies addressing strategies to enhance RTW after SCI. ${ }^{16}{ }^{17}$ Our study indicates strengths of ReWork-SCI compared with the experiences of an otherwise fragmented support in RTW in a Swedish context. ${ }^{3-5} 10$ Our findings generate critical knowledge about the intervention in a clinical setting, this is important in a next step towards further development and evaluation of ReWork-SCI. In terms of design, our study demonstrates good retention and possible primary and secondary outcomes for evaluating the effectiveness of ReWork-SCI. For such an effectiveness in a Swedish setting we recommend cluster randomisation in multiple sites. Prior to an effectiveness study, uncertainties regarding sample size and recruitment need to be considered.

\section{CONCLUSION}

This study shows that ReWork-SCI was feasible but further modelling and modification are needed for the intervention to be applicable in a clinical context and sufficiently person-centred. Moreover, certain aspects of design need to be considered prior to future studies. Core features were, that the design builds on a systematic structure, the use of a person-centred approach and the individualised dialogue with the employer supported by a coordinator. ReWork-SCI could contribute to creating a plan for RTW, facilitate decision-making and build trust in the RTW process. Therefore, further development and evaluation of ReWork-SCI are relevant.

Acknowledgements We would like to express our appreciation to the participants, who, by sharing their time and experiences, made this study possible. We thank the coordinators, who, through their commitment and expertise, enabled evaluation of the feasibility of ReWork-SCl. Lastly, we thank Tobias Holmlund for valuable support in management and analysis of the data.

Contributors LH, EA and SG conceived the original idea, and all authors contributed to the outline and design of the study. LH has been responsible for developing the intervention in collaboration with all co-authors. LH, EA, CH and ÅS have been responsible for collaboration with the regional rehabilitation centre, while LH, GE and SG were responsible for training the coordinators. LH and EA were responsible for data collection. LH has been the main author and all co-authors discussed, contributed and commented on draft versions and approved the final version.

Funding This work was supported by the Doctoral School in Healthcare Sciences at Karolinska Institutet (Dnr 2-1955/2013), Norrbacka-Eugenia Foundation and Praktikertjänst Inc.

Patient consent for publication Not required.

Ethics approval Ethical approval was obtained from the regional Ethical Review Board in Stockholm (Reg.no.: 2017/4:7).

Provenance and peer review Not commissioned; externally peer reviewed.

Data availability statement Data are available upon reasonable request.

Open access This is an open access article distributed in accordance with the Creative Commons Attribution Non Commercial (CC BY-NC 4.0) license, which permits others to distribute, remix, adapt, build upon this work non-commercially, and license their derivative works on different terms, provided the original work is properly cited, appropriate credit is given, any changes made indicated, and the use is non-commercial. See: http://creativecommons.org/licenses/by-nc/4.0/.

\section{ORCID iDs}

Lisa Holmlund http://orcid.org/0000-0001-8321-0174

Susanne Guidetti http://orcid.org/0000-0001-6878-6394 


\section{REFERENCES}

1 Fadyl JK, McPherson KM. Understanding decisions about work after spinal cord injury. J Occup Rehabil 2010;20:69-80.

2 Hay-Smith EJC, Dickson B, Nunnerley J, et al. "The final piece of the puzzle to fit in": an interpretative phenomenological analysis of the return to employment in New Zealand after spinal cord injury. Disabil Rehabil 2013;35:1436-46.

3 Holmlund L, Guidetti S, Eriksson G, et al. Return to work in the context of everyday life 7-11 years after spinal cord injury - a followup study. Disabil Rehabil 2018;40:2875-83.

4 Holmlund L, Hultling C, Asaba E. Mapping out one's own paths toward work: focus on experiences of return to work after spinal cord injury. Qual Health Res 2018;28:2020-32.

5 Bergmark L, Westgren N, Asaba E. Returning to work after spinal cord injury: exploring young adults' early expectations and experience. Disabil Rehabil 2011;33:2553-8.

6 Ottomanelli L, Lind L. Review of critical factors related to employment after spinal cord injury: implications for research and vocational services. J Spinal Cord Med 2009;32:503-31.

7 Levi R, Hultling C, Seiger A. The Stockholm spinal cord injury study: 4. psychosocial and financial issues of the Swedish annual level-of-living survey in SCl subjects and controls. Paraplegia 1996;34:152-7.

8 Valtonen K, Karlsson A-K, Alaranta H, et al. Work participation among persons with traumatic spinal cord injury and meningomyelocele1. $J$ Rehabil Med 2006;38:192-200.

9 United Nations. Convention on the rights of persons with disabilitiesoptional protocol [online], 2006. Available: https://www.un.org/ development/desa/disabilities/convention-on-the-rights-of-personswith-disabilities.html [Accessed 01 Dec 2018].

10 Holmlund L, Guidetti S, Eriksson G, et al. Return-To-Work: exploring professionals' experiences of support for persons with spinal cord injury. Scand J Occup Ther 2020:1-11.

11 Craig P, Dieppe P, Macintyre S, et al. Developing and evaluating complex interventions: the new medical Research Council guidance. BMJ 2008;337:a1655.

12 Vogel N, Schandelmaier S, Zumbrunn T, et al. Return-to-work coordination programmes for improving return to work in workers on sick leave. Cochrane Database Syst Rev 2017;3:CD011618.

13 Cullen KL, Irvin E, Collie A, et al. Effectiveness of workplace interventions in return-to-work for musculoskeletal, pain-related and mental health conditions: an update of the evidence and messages for practitioners. J Occup Rehabil 2018;28:1-15.

14 Hoefsmit N, Houkes I, Nijhuis FJN. Intervention characteristics that facilitate return to work after sickness absence: a systematic literature review. J Occup Rehabil 2012;22:462-77.

15 Schandelmaier S, Ebrahim S, Burkhardt SCA, et al. Return to work coordination programmes for work disability: a meta-analysis of randomised controlled trials. PLoS One 2012;7:e49760.

16 Roels EH, Aertgeerts B, Ramaekers D, et al. Hospital- and community-based interventions enhancing (re)employment for people with spinal cord injury: a systematic review. Spinal Cord 2016;54:2-7.

17 Trenaman LM, Miller WC, Escorpizo R, et al. Interventions for improving employment outcomes among individuals with spinal cord injury: a systematic review. Spinal Cord 2014;52:788-94.

18 Ottomanelli L, Goetz LL, Suris A, et al. Effectiveness of supported employment for veterans with spinal cord injuries: results from a randomized multisite study. Arch Phys Med Rehabil 2012;93:740-7.

19 Ottomanelli L, Barnett SD, Goetz LL. Effectiveness of supported employment for veterans with spinal cord injury: 2-year results. Arch Phys Med Rehabil 2014;95:784-90.

20 Middleton JW, Johnston D, Murphy G, et al. Early access to vocational rehabilitation for spinal cord injury inpatients. J Rehabil Med 2015;47:626-31.

21 Hilton G, Unsworth CA, Murphy GC, et al. Longitudinal employment outcomes of an early intervention vocational rehabilitation service for people admitted to rehabilitation with a traumatic spinal cord injury. Spinal Cord 2017;55:743-52.

22 Moore GF, Audrey S, Barker M, et al. Process evaluation of complex interventions: medical Research Council guidance. BMJ 2015;350:h1258.

23 Ottomanelli L, Barnett S, Goetz LL, et al. Vocational rehabilitation in spinal cord injury: what vocational service activities are associated with employment program outcome? Top Spinal Cord Inj Rehabil 2015;21:31-9.

24 Ramakrishnan K, Johnston D, Garth B, et al. Early access to vocational rehabilitation for inpatients with spinal cord injury: a qualitative study of patients' perceptions. Top Spinal Cord Inj Rehabil 2016;22:183-91.
25 Johnston D, Ramakrishnan K, Garth B, et al. Early access to vocational rehabilitation for inpatients with spinal cord injury: a qualitative study of staff perceptions. J Rehabil Med 2016;48:776-80.

26 Ståhl C, Costa-Black K, Loisel P. Applying theories to better understand socio-political challenges in implementing evidencebased work disability prevention strategies. Disabil Rehabil 2018;40:952-9.

27 Loisel P, Buchbinder R, Hazard R, et al. Prevention of work disability due to musculoskeletal disorders: the challenge of implementing evidence. J Occup Rehabil 2005;15:507-24.

28 Arain M, Campbell MJ, Cooper CL, et al. What is a pilot or feasibility study? A review of current practice and editorial policy. BMC Med Res Methodol 2010;10:67.

29 Tickle-Degnen L. Nuts and bolts of conducting feasibility studies. Am J Occup Ther 2013;67:171-6.

30 Bowen DJ, Kreuter M, Spring B, et al. How we design feasibility studies. Am J Prev Med 2009;36:452-7.

31 O'Cathain A, Hoddinott P, Lewin S, et al. Maximising the impact of qualitative research in feasibility studies for randomised controlled trials: guidance for researchers. Pilot Feasibility Stud 2015;1:32.

32 Wilcock AA, Hocking C. An occupational perspective of health. Thorofare: Slack, 2015.

33 Leplege A, Gzil F, Cammelli M, et al. Person-centredness: conceptual and historical perspectives. Disabil Rehabil 2007;29:1555-65.

34 Balbale SN, Locatelli SM, LaVela SL. Through their eyes: lessons learned using participatory methods in health care quality improvement projects. Qual Health Res 2016;26:1382-92.

35 Ekman I, Swedberg K, Taft C, et al. Person-centered care--ready for prime time. Eur J Cardiovasc Nurs 2011;10:248-51.

36 Hertzog MA. Considerations in determining sample size for pilot studies. Res Nurs Health 2008;31:180-91.

37 Kirshblum SC, Burns SP, Biering-Sorensen F, et al. International standards for neurological classification of spinal cord injury (revised 2011). J Spinal Cord Med 2011;34:535-46.

38 Law M, Baptiste S, McColl M, et al. The Canadian occupational performance measure: an outcome measure for occupational therapy. Can J Occup Ther 1990;57:82-7.

39 Law M, Carswell A, McColl MA, et al. Canadian occupational performance measure. 4th ed. Toronto: Canada: Canadian Association of Occupational Therapists, 2005.

40 Braveman BR, Velozo M, Kielhofner, G C, et al. Worker role interview (WRI). version 10.0. Chicago: University of Illinois, 2005.

41 Forsyth K, Braveman B, Kielhofner G, et al. Psychometric properties of the worker role interview. Work 2006;27:313-8.

42 Ekbladh E, Thorell L-H, Haglund L. Return to work: the predictive value of the worker role interview (WRI) over two years. Work 2010;35:163-72.

43 Moore-Corner RAK, Olsson, L G. Work environment impact scale (WEIS) version 2.0. Chicago: Model of Human Occupation Clearinghouse, University of Illinois, 1998.

44 Ekbladh E, Fan C-W, Sandqvist J, et al. Work environment impact scale: testing the psychometric properties of the Swedish version. Work 2014;47:213-9.

45 Fugl-Meyer AR, Melin R, Fugl-Meyer KS. Life satisfaction in 18 to 64-year-old Swedes: in relation to gender, age, partner and immigrant status. J Rehabil Med 2002;34:239-46.

46 Ekstrand $\mathrm{E}$, Lexell J, Brogårdh $\mathrm{C}$. Test-Retest reliability of the life satisfaction questionnaire (LiSat-11) and association between items in individuals with chronic stroke. J Rehabil Med 2018:50:713-8.

47 Bandura A. Social foundations of thought and action: a social cognitive theory. Englewood Cliffs: Prentice-Hall, Inc, 1986.

48 Altmaier EM, Russell DW, Kao CF, et al. Role of self-efficacy in rehabilitation outcome among chronic low back pain patients. $J$ Couns Psychol 1993;40:335-9.

49 Rabin R, de Charro F. EQ-5D: a measure of health status from the EuroQol group. Ann Med 2001;33:337-43.

50 Burström K, Sun S, Gerdtham U-G, et al. Swedish experience-based value sets for EQ-5D health states. Qual Life Res 2014;23:431-42.

51 Antonovsky A. Unraveling the mystery of health: how people manage stress and stay well. San Francisco: Jossey-Bass, 1987.

52 Mittelmark MB, Sagy S, Eriksson M, et al. The handbook of salutogenesis. Cham: Springer International Publishing, 2017.

53 Eriksson M, Lindström B. Validity of Antonovsky's sense of coherence scale: a systematic review. J Epidemiol Community Health 2005;59:460-6.

54 Guide for the uniform data set for medical rehabilitation (Adult FIMTM). Version 5.0. Buffalo: State University of New York, 1996.

55 Hall KM, Cohen ME, Wright J, et al. Characteristics of the functional independence measure in traumatic spinal cord injury. Arch Phys Med Rehabil 1999;80:1471-6. 
56 Boyatzis RE. Transforming qualitative information : thematic analysis and code development. London: Sage, 1998.

57 Ayres L. Thematic coding and analysis. In: Given L, ed. The SAGE encyclopedia of qualitative research methods. Thousand Oaks: Sage Online, 2008. http://sk.sagepub.com/reference/research

58 Friese S. Qualitative data analysis with ATLAS.ti. London: Sage, 2014.

59 Ranner M, von Koch L, Guidetti S, et al. Client-centred ADL intervention after stroke: occupational therapists' experiences. Scand $J$ Occup Ther 2016;23:81-90.

60 Ranner M, Guidetti S, von Koch L, et al. Experiences of participating in a client-centred ADL intervention after stroke. Disabil Rehabil 2018:1-9.

61 Franche R-L, Cullen K, Clarke J, et al. Workplace-based return-towork interventions: a systematic review of the quantitative literature. J Occup Rehabil 2005;15:607-31.

62 van Vilsteren M, van Oostrom SH, de Vet HCW, et al. Workplace interventions to prevent work disability in workers on sick leave. Cochrane Database Syst Rev 2015;10:CD006955.

63 Arends I, van der Klink JJL, van Rhenen W, et al. Prevention of recurrent sickness absence in workers with common mental disorders: results of a cluster-randomised controlled trial. Occup Environ Med 2014;71:21-9.
64 Wressle E, Eeg-Olofsson A-M, Marcusson J, et al. Improved client participation in the rehabilitation process using a client-centred goal formulation structure. J Rehabil Med 2002;34:5-11.

65 Pfadenhauer LM, Gerhardus A, Mozygemba K, et al. Making sense of complexity in context and implementation: the context and implementation of complex interventions $(\mathrm{ClCl})$ framework. Implement Sci 2017;12:21.

66 Nunnerley JL, Hay-Smith EJC, Dean SG. Leaving a spinal unit and returning to the wider community: an interpretative phenomenological analysis. Disabil Rehabil 2013;35:1164-73.

67 Krause JS. Years to employment after spinal cord injury. Arch Phys Med Rehabil 2003;84:1282-9.

68 Yngve M, Ekbladh E. Clinical utility of the worker role interview: a survey study among Swedish users. Scand J Occup Ther 2015;22:416-23.

69 Wressle E, Marcusson J, Henriksson C. Clinical utility of the Canadian Occupational Performance Measure--Swedish version. Can J Occup Ther 2002;69:40-8.

70 Joseph C, Andersson N, Bjelak S, et al. Incidence, aetiology and injury characteristics of traumatic spinal cord injury in Stockholm, Sweden: a prospective, population-based update. $J$ Rehabil Med 2017;49:431-6. 